\title{
Kalp Kapakları Bize ne Diyor?
}

\section{What Do The Heart Valves Tell Us?}

\author{
Sezen KOCCARSLAN ${ }^{1}$ (D), Aydemir KOÇARSLAN 2 (D), Mehmet KiRişçil 2 (D), Erdinç EROĞLU 2 (D) \\ Mehmet ACIPAYAM $2{ }^{\mathbb{D}}$, Alptekin YASIM ${ }^{2}$
}

\begin{abstract}
1 Kahramanmaraş Sütçü İmam Üniversitesi Tıp Fakültesi Patoloji AD.
2 Kahramanmaraş Sütçü İmam Üniversitesi Kalp ve Damar Cerrahisi AD.
\end{abstract}

Öz.

Amaç: Çalışmamızın amacı dejeneratif kalp kapak hastalıkları nedeniyle eksize kalp kapakçıklarının histopatolojik değişikliklerini araştırmaktır.

Materyal ve metod : Dejeneratif kalp kapağı hastalığı olan 40 hastadan eksize edilen 28 tane aort kapağı ile 20 tane mitral kapak retrospektif olarak araştırmaya dahil edildi. 8 hastadan hem aort hem mitral kapak eksize edilmiştir. Hastalara ait klinik diagnostik bilgiler hastane bilgi sisteminden elde edildi. Kalp kapakları standart histopatolojik metotlar kullanılarak parafine gömüldü ve her bloktan 3-4 $\mu \mathrm{m}$ kalınlığında kesitler alındı. Hematoksilen Eozin ile boyalı preparatlar Olympus BX51 mikroskopu ile histopatolojik değişiklikler açısından değerlendirildi. Her vakanın mevcut histopatolojik slaytları orijinal tanıyı doğrulamak ve çeşitli mikroskobik değişikliklerin değerlendirmesini sağlamak için bağımsız olarak gözden geçirildi.

Bulgular: Hastaların 21(\% 53)' i erkek, 19(\% 47)' u kadındı. Hastaların yaş aralı̆ı̆ 20-88 idi. Ortalama yaş 59 olarak hesaplandı. Kadınların yaş ortalaması 60.7 , erkeklerin yaş ortalaması 57.5 idi. Hastane bilgi sisteminden edinilen verilere göre hastaların 14 (\% 35)'ünde hipertansiyon, 12 (\% 30)'sinde hiperlipidemi, 9 (\% 23)'unda diyabetes mellitus, 10 (\% 25)'unda sigara öyküsü $6(\%$ 15)'sında koroner arter hastalı̆ı ı mevcuttu. Fokal alanlarda normal histolojik yapının da seçilebildiği kapakların tamamında $(\%$ 100) değişen derecelerde fibrozis mevcuttu . 32 kapakta (\% 67) kalsifikasyon mevcuttu. Altı kapakta (\% 13) kemik ve kartilaj oluşumu birlikte izlendi . Kemik ve kartilaj oluşumu izlenen kapakların 4 (\% 8)'ü aort, 2 (\%4)'si mitral kapaktı. Tüm kemik oluşumu alanlarına kalsifikasyon da esslik etmekteydi. Kemik metaplazisi görülme yaş ortalaması 60.8 idi. 27 kapakta (\% 56) kronik inflamasyon, 11 kapakta (\% 23) neoanjiogenezis ve bir kapakta (\% 2) endokardite bağı nekroz ve abse formasyonu izlendi Kronik inflamasyonun lenfositler ve plazma hücrelerinden oluștuğu görüldü.

Sonuç: Kalp kapak dejenerasyonları kardiyovasküler risk faktörleri ile yakından ilişkilidir. Çok basamaklı moleküler yolaklar aracılığıyla gelişen aktif bir süreçtir. Kapak interstisyel hücreleri bu süreçteki başrol oyuncusudur.

Anahtar Kelimeler: Kalp kapakları, Dejenerasyon, Histopatoloji.

Abstract

Background: The aim of our study was to investigate the histopathological changes of excised cardiac valves due to degenerative heart valve diseases.

Methods: We collected and explored the histopathologic changes in 28 aortic valves and 20 mitral valves from 40 patients with Acquired Heart Valve Disease retrospectively. Both aorta and mitral valve were excised from 8 patients. Clinical diagnostic information about the patients was obtained from the hospital information system. Fragments of cardiac valve were processed using standard histopathological methods and embedded in paraffin tissue blocks. From each block, 3-4 $\mu \mathrm{m}$-thick histological sections were cut and stained with hematoxylin-eosin. Slides stained with hematoxylin-eosin were evaluated under Olympus BX51 microscope for histopathological changes. In each case, the available histopathological slides were independently reviewed to confirm the original diagnosis and provide assessment of the various microscopic changes.

Results: $21(53 \%)$ of the patients were male and $19(47 \%)$ were female. The age range of the patients was 20-88. The average age was calculated to be 59. The average age of women was 60.7 and the average age of men was 57.5. According to the data obtained from the hospital information system, hypertension in $14(35 \%)$, hyperlipidemia in $12(30 \%)$, diabetes in $9(23 \%)$, smoking history in $10(25 \%)$ and coronary artery disease in $6(15 \%)$ were present. There were varying degrees of fibrosis in all of the valves (100\%) in which the normal histological structure was also observed in the focal areas. Calcification was present on 32 valves $(67 \%)$. Six valves (13\%) showed both bone and cartilage formation. The valves which exhibit bone and cartilage formation were 4 valves (8\%) aorta and 2 valves (8\%) mitral valve. All areas of bone formation were accompanied by calcification. The average age of bone metaplasia was 60.8 . Chronic inflammation was observed in 27 valves (56\%). Neoangiogenesis in 11 valves (23\%) and necrosis and abscess formation due to endocarditis in one valve (2\%) were observed. Chronic inflammation consisted of lymphocytes and plasma cells.

Conclusion: Heart valve degenerations are closely associated with cardiovascular risk factors. it is an active process that develops through multi-step molecular pathways. Valve interstitial cells are the lead player in this process.

Key words: Heart Valves, Degeneration, Histopathology

\section{Sorumlu Yazar I \\ Corresponding Author}

Doç. Dr. Sezen KOÇARSLAN Kahramanmaraş Sütçü İmam Üniversitesi Tıp Fakültesi Patoloji AD.

\section{Kahramanmaraş Sütçü İmam Üniversitesi Tıp Fakültesi Eğitim Araştırma Hastanesi Avşar Mah, Batı Çevreyolu Blv $251 / A, 46000$ \\ Onikişubat/Kahramanmaraş}

Tel: 03443003408

Faks: 03443003409

e-mail: doktorsezen@yahoo.com

Geliş tarihi / Received: 06.05.2020

Kabul tarihi / Accepted: 08.06.2020

DOI: $10.35440 /$ hutfd.732991 


\section{Giriş}

Kalp kapakları kompleks çok tabakalı yapılardır. Fibroblastlar, mezenkimal interstisyel hücreler, kollajen fibriller, elastik lifler ve bol miktarda proteoglikanlardan oluşur. Yaşa bağlı olarak kapaklarda kalınlaşma, opaklaşma, esneklik kaybı ve kapak çevresinde genişleme görülür. Yaşa bağlı bu değişikliklerin kollajen lif miktarındaki artışına bağlı olarak ortaya çıktığı düşünülmektedir $(1,2)$. Ancak çeşitli kapak hastalıkları nedeniyle cerrahi olarak eksize edilen kalp kapak materyallerinin histopatolojik incelenmesinde kıkırdak ve kemik doku oluşumu, kalsifikasyon ve inflamasyon gibi çok çeşitli patolojik bulguların varlığından söz edilmektedir $(3,4)$. Biz de bu çalışmada kalp kapaklarında gördüğümüz histopatolojik bulguları ve bunların nedenlerini literatür bilgileri eşliğinde sunmayı hedefledik.

\section{Materyal ve Metod}

Bu histopatolojik çalışma Kahramanmaraş Sütçü İmam Üniversitesi Klinik araştırmalar etik kurulundan izin alınarak (16/05/2018 tarih, 19 nolu karar), Tibbi Patoloji ve Kalp Damar Cerrahisi Anabilim dallarında yapıımıştır. 20162020 yılları arasında, edinilmiş kalp kapağı hastalığı nedeniyle opere edilen 40 hastadan eksize edilen 28 tane aort kapağı ile 20 tane mitral kapak retrospektif olarak araştırmaya dahil edilmiştir. 8 hastanın hem aort hem mitral kapak materyalleri mevcuttu. Hastalara ait klinik diagnostik bilgiler hastane bilgi sisteminden elde edilmiştir. Kalp kapakları standart histopatolojik metotlar kullanılarak parafine gömülmüş ve her bloktan 3-4 $\mu \mathrm{m}$ kalınlığında kesitler alınmıştır. Hematoksilen\&Eozin ile boyalı preparatlar Olympus BX51 mikroskopu ile değerlendirilmiştir. Her vakanın mevcut histopatolojik slaytları orijinal tanıyı doğrulamak ve çeşitli mikroskobik değişikliklerin değerlendirmesini sağlamak için bağımsız olarak gözden geçirildi.

\section{Bulgular}

Hastaların 21(\% 53)' i erkek, 19(\% 47)' u kadındı. Hastaların yaş aralığı 20-88 idi. Ortalama yaş 59 olarak hesaplandı. Kadınların yaş ortalaması 60.7 , erkeklerin yaş ortalaması 57.5 idi. Hastane bilgi sisteminden edinilen verilere göre hastaların 14 (\% 35)'ünde hipertansiyon, 12 (\% 30)'sinde hiperlipidemi, 9 (\% 23)'unda diyabetes mellitus, 10 (\% 25)'unda sigara öyküsü 6 (\% 15)'sında koroner arter hastalığı mevcuttu. Fokal alanlarda normal histolojik yapının da seçilebildiği kapakların tamamında (\% 100) değişen derecelerde fibrozis mevcuttu (Resim 1a,1b). 32 kapakta (\% 67) kalsifikasyon mevcuttu (Resim 2). Altı kapakta (\% 13) kemik ve kartilaj oluşumu birlikte izlendi ( Resim 3). Kemik ve kartilaj oluşumu izlenen kapakların 4 (\% 8)'ü aort, $2(\% 4)$ 'si mitral kapaktı. Tüm kemik oluşumu alanlarına kalsifikasyon da eşlik etmekteydi. Kemik metaplazisi görülme yaş ortalaması 60.8 idi. 27 kapakta (\% 56) kronik inflamasyon, 11 kapakta (\% 23) neoanjiogenezis ve bir kapakta (\% 2) endokardite bağlı nekroz ve abse formasyonu izlendi Kronik inflamasyonun lenfositler ve plazma hücrelerinden oluştuğu görüldü. (Resim 4a,b).

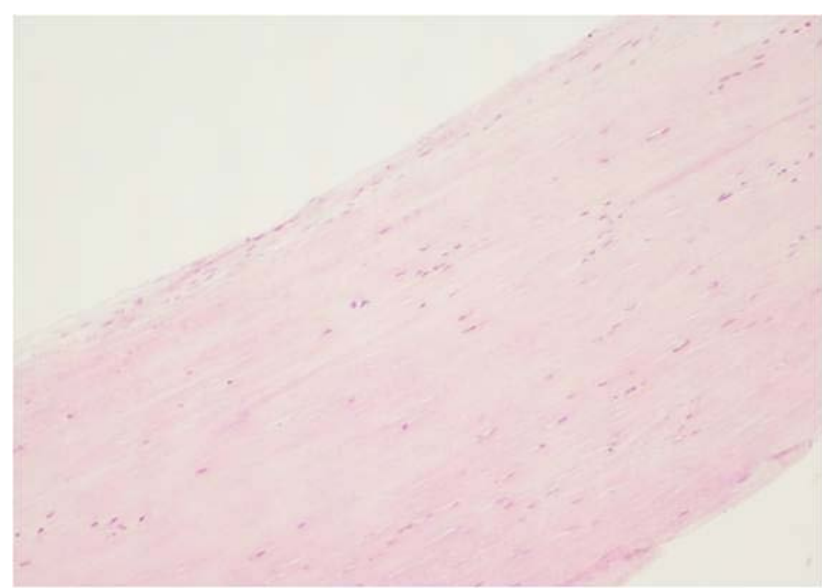

Resim 1a. Histopatolojik kesitte normal histolojik yapının korunduğu bir kalp kapağına ait yapı izlenmektedir (Hematoksilen\&Eozin X100 objektif)

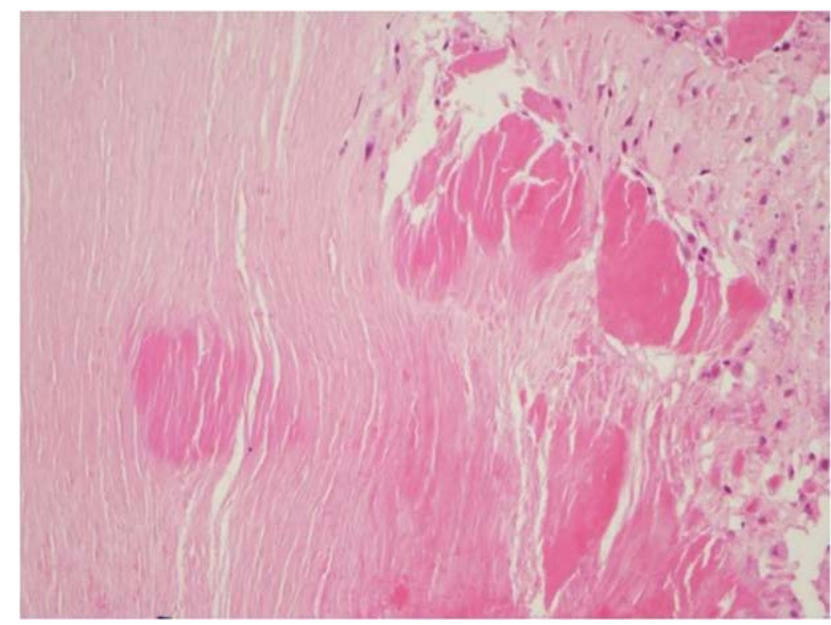

Resim 1b. Kaba kalın kollajen liflerden oluşan fibrozis alanı izlenmektedir (Hematoksilen\&Eozin X200 objektif)

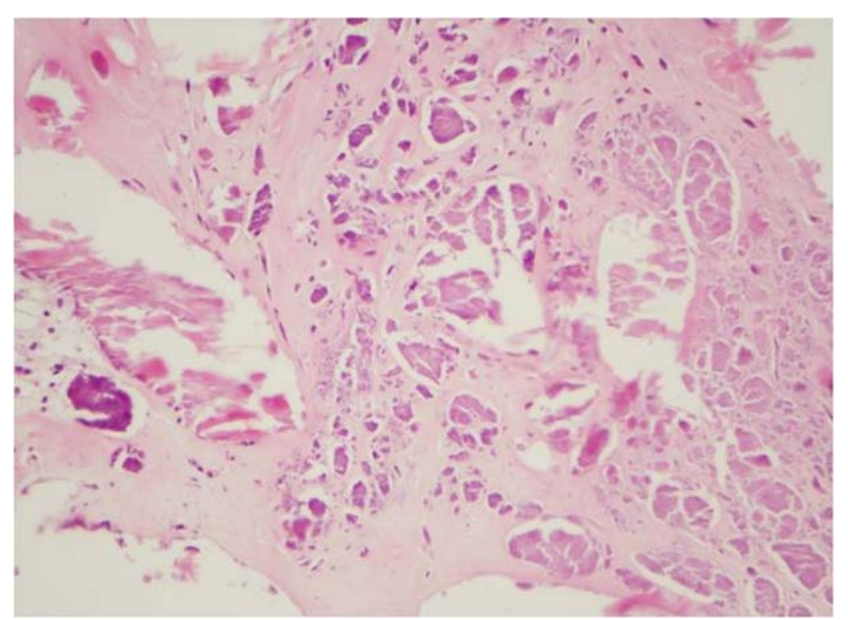

Resim 2. Bazofilik boyanan amorf granüler kalsifikasyon alanı izlenmektedir (Hematoksilen\&Eozin X200 objektif) 


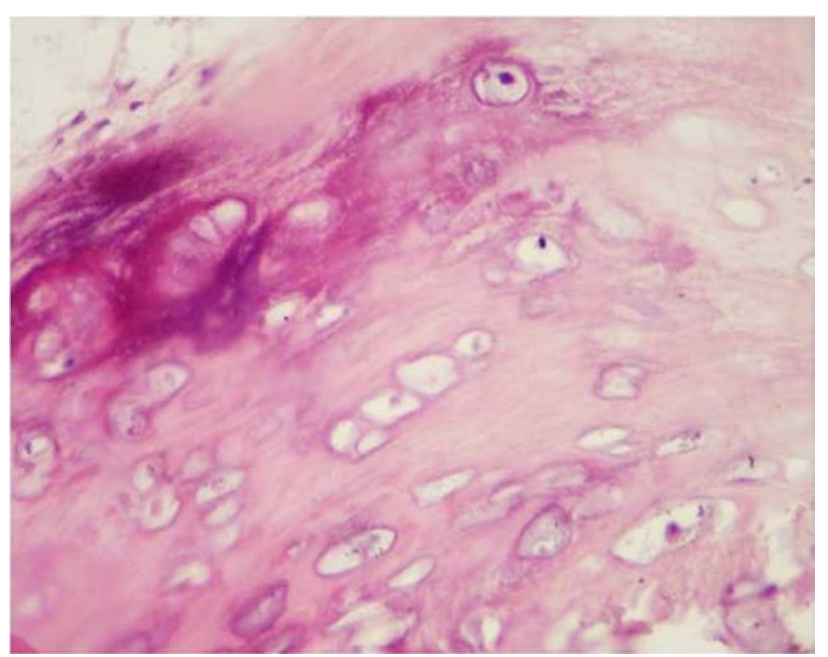

Resim 3. Kısmen kalsifiye osseo-kondromatöz metaplazi alanı izlenmektedir (Hematoksilen\&Eozin X400 objektif)

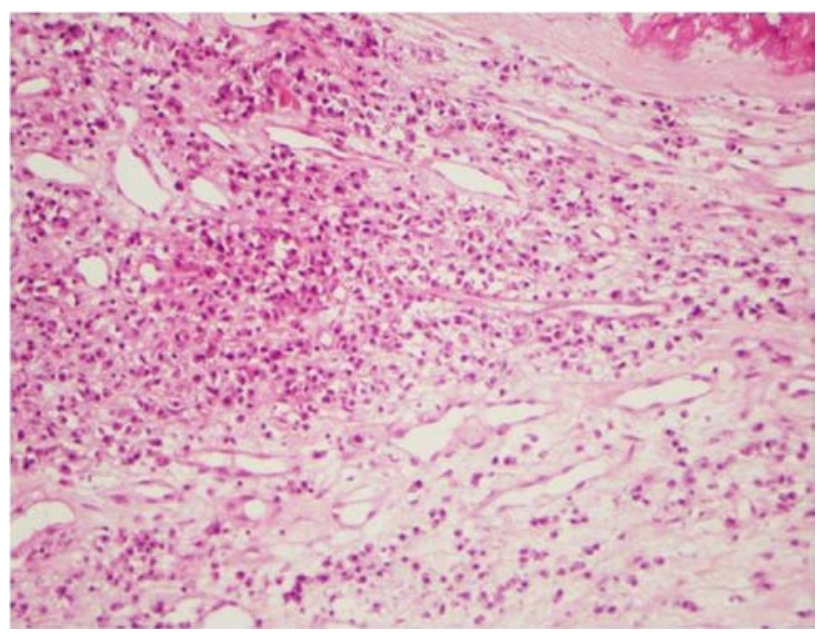

Resim 4a. Çoğunluğu plazma hücresinden ve kısmen lenfositlerden oluşan kronik inflamasyon ve neoanjiogenezis alanı izlenmektedir (Hematoksilen\&Eozin X400 objektif)

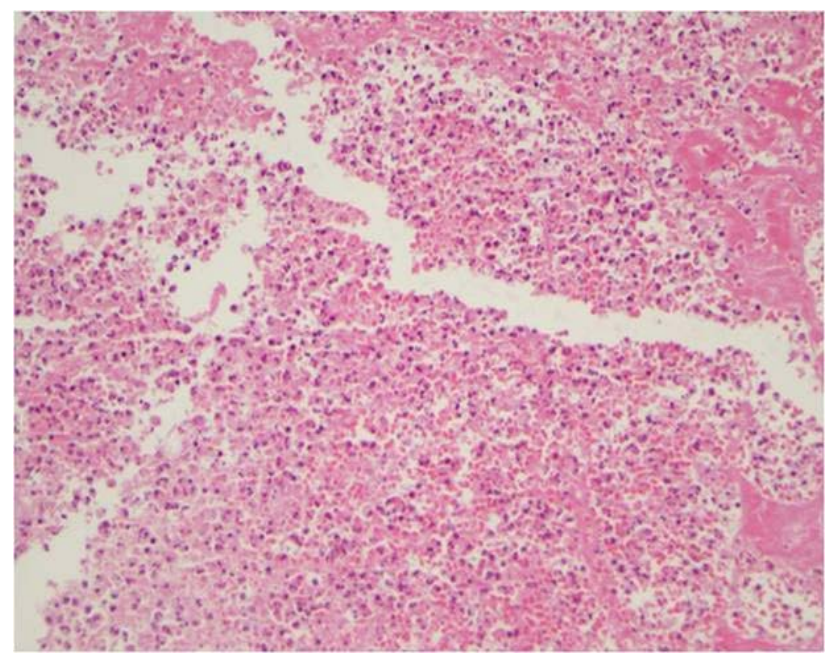

Resim 4b. Endokardite bağlı abseleşen nekroz alanları izlenmektedir (Hematoksilen\&Eozin X200 objektif)

\section{Tartışma}

Kalp kapakçıkları, yaşam boyu her kalp kontraksiyonuyla birlikte tekrarlayan, yüksek seviyelerde mekanik strese maruz kalır. Bu nedenle, fonksiyon bozukluğuna yol açan kümülatif hasara ve dejenerasyona uğraması şaşırtıcı değildir. Ayrıca konjenital biküspid aort kapak (BAK), mitral kapak prolapsusu ve romatizmal kalp hastalığı gibi durumlar da hasarın ve dejenerasyonun hız ve şiddetini daha da artırmaktadır $(1,2)$. Literatürde edinsel kalp kapak hastalıkları nedeniyle eksize edilen dejenere kapakların histopatolojik incelenmesinde kronik inflamasyon, kalsifikasyon, fibrozis, angiogenez, hemoraji, osseöz ve kartilajinöz metaplazi, adipojenik metaplazi gibi çok çeşitli bulgular saptanmıştır. Günümüze kadar yapılan araştırmalar dejeneratif kapak hastalıklarının patofizyolojisinin çok karmaşık olduğunu göstermiştir. Önceki çalışmalarda en sık aortta görülen kapak kalsifikasyonunun, wear and tear (aşınma ve yıpranma) dejenerasyonuna bağlı olarak pasif distrofik kalsifikasyon sürecinin bir parçası olarak kabul ediliyordu. Ancak daha yeni çalışmalar hipertansiyon, hiperlipidemi ve kronik inflamasyon gibi aterosklerozda görülen predispoze faktörlerin neden olduğu kronik hasarın kalsifikasyon patogenezinde de etkili olduğunu ve hatta kalsifikasyondan önce gelebileceğini göstermiştir. Bizim çalışmamızda da hastaların birçoğunda kapak dejenerasyonu için predispose faktörler olan hipertansiyon, hiperlipidemi, Diyabetes Mellitus ve çeşitli kardiyak vasküler hastalıklara sahipti. Bununla birlikte aterosklerozdan farklı olarak kalsifiye kapaklarda düz kas hücresi yerine osteoblasta benzeyen kapak interstisyel hücrelerinin $(\mathrm{KIH})$ var olduğu ve bu hücrelerin kemik matriks proteinleri senteleyerek kalsifikasyona ve ossifikasyona yol açtığı görülmüştür. (1-3). Galli ve ark.'nın in vivo çalışmasında kültür ettikleri KïH'lerin, uygun moleküler stimuluslar altında osteoblast, kondrosit ve adiposit gibi çok çeşitli metaplastik mezenkimal hücrelere diferansiasyon potansiyeline sahip olduklarını kanıtlamışlardir. İ vivo olarak hayat boyu günde 100000 siklus boyunca yüksek tansiyon ve dengelenmemiş kompresyon sonucu olarak stabil KiH'lerin tamamen diferansiye metaplastik hücrelere değişiminin ortaya çıktığını göstermişlerdir. Kalsifik aort stenozlu 236 vakadan oluşan çalışmasında şiddetli fibrozis (\%100), kalsifiye nodüller (\%100), neoangiogenezis (\% 81), inflamasyon (\% 71), kemik metaplazisi (\% 6), adipojenik metaplazi (\% 16), ve kartilajinöz metaplazi (\% 7)bulgularını izlemişlerdir. Bu histopatolojik bulguların hastalığın şiddeti ile ilişkili olduğunu vurgulamışlardır (3). Bizim çalışmamızda da değişen oranlarda fibrozis, kalsifikasyon, osseo-kondromatöz metaplazi ve neoanjiogenezisile kronik inflamasyon bulguları mevcuttu. Steiner ve ark. 178 kalsifiye aort kapağı incelenmesinde $\% 84.8$ oranında kronik inflamasyon izlemişler ve kalsifiye aort stenozunun patogenezinde kronik inflamasyon zemininde KiH'lerin baş rolü olduğunu belirtmişlerdir (5). Mohler ve arkadaşları kalsifiye kalp kaาpaklarından kültüre ettikleri miyofibroblast 
benzeri hücrelerin osteoblast benzeri hücrelere fenotipik differansiasyon gösterdiklerini ve kemik matriks pro־tein ile pozitif boyandıklarını saptamışlardır (6). Yine çeşitli çaIışmalar da kalsifiye kalp kapaklarında osteonektin, osteokalsin ve osteopontin gibi çeşitli kemik proteinlerinin bulunduğunu rapor etmişlerdir. Steiner ve ark.'nın yaptığı çalışmada cerrahi olarak eksize edilen 1177 kalp kapağının histolo?jik incelenmesinde yaklaşık \% 11 oranında kemik ve/veya kartilaj formasyonu izlemişlerdir $(7,8)$. Kalsifiye kapaklardaki kıkırdak oluşumunun, kemikte kırık iyileşmesinde görülene benzer şekilde endokondral ossifikasyon ile devamlıık gösterdiği saptanmıştır $(9,10)$. Çalışmamızda da kartilaj ve kemik oluşumu beraberdi ve kalsifikasyon eşlik etmekteydi. Torre ve ark.'ları kalsifik aort kapaklarında \%15.6 oranında osseöz ve/veya kondromatöz metaplazinin görüldüğünü, bu oranın BAK'ta \%30.1'e yükseldiğini bildirmiştir. BAK, triküspit aortik kapak ve protez kapakları biribiri ile kıyasladığında; prostetik kapakta sadece kalsifikasyonun görüldüğünü, osteojenik veya kondrojenik metaplazi gibi metaplazi türlerinin görülmediğini saptamıştır. Protez kapaklarda görülen kalsifikasyonun distrofik kalsifikasyon olduğuna değinmiş, KiH'leri olmadığı için osteojenik ve kondrojenik metaplazi oluşmadığını savunmuştur. Triküspit ve BAK'larındaki osteojenik ve kondrojenik metaplazi oluşumundan KiH'lerin sorumlu olduğunu ileri sürmüştür Ayrıca BAK' ının daha yüksek oranda metaplazi göstermesini daha fazla anormal hemodinamik basınca maruziyeti ile ilişkili olduğunu vurgulamıştır. Erkek cinsiyet, ateroskleroz veya kronik böbrek hastalığı varlığı gibi durumunda metaplazi görülme oranının arttığını bildirmişlerdir (4). Akahori ve ark.'ları aort stenozunun damar aterosklerozu ile aynı ortak mekanizmalar ile geliştiğini ve inflamasyon, hemoraji ve anjiogenezin aort stenozu gelişiminde kritik bir rol oynadığını ileri sürmüştür (11). Literatürdeki çaIışmalarda da görüldüğü üzere kronik hasarlayıcı faktörlere sekonder olarak KIH'lerin aktive olup, bir yanıt oluşturduğu aşikârdır. Ancak KiH'lerin yanıt olarak osteojenik, kondrojenik veya adipojenik hücrelere nasıl diferansiasyon gösterdiği henüz net olarak açıklanamamıştır. İn vivo moleküler çalışmalar; kronik haרsara cevap olarak makrofajların koordinasyonunda IL1 $\beta$, IL6, IL8, TNF- $\alpha$, IGF-1,TGF- $\beta$ gibi sitokinlerin aracılığıyla KiH'lerin diferansiasyona uğradığını göstermektedir (12-14). Vasküler yatakta aterosklerozda rol oynayan subendotelyal peri-ssit benzeri düz kas hücre ağı gibi, kalp kapaklarındaki histopatolojik değişikliklerden sorumlu olan, fibröz tabaka boyunca yerleşmiş, miyofibroblasta benzeyen KiH'ler mevcuttur. Kronik hemodinamik ha sara bağlı olarak kan dolaşımındaki lenfositler, monositler ve mast hücreleri kalp kapağına girer ve orada çeşitli pro-inflamatuar moleküller, sitokinler ve kemokinler salgılayarak miyofibroblast benzeri KiH'leri uyarırlar. Aktive olan KiH'ler osteojenik, adipojenik veya kondrojenik hücrelere fenotipik diferansias-yon gösterirler $(15,16)$. Hemodi- namik stres altındaki KiH'ler oksitlenmiş lipid türleri ile karşılaştığında kapak içinde lipid birikimi başlar. Bu durumda KiH'ler tarafından eksprese edilen toll like reseptörler (TLRs) ve NF-kB yoluyla doğal immün yanıt aktive edilir. Böylelikle kapakta B ve T lenfositler (CD4+ / CD8 + hücre oranı 3:1) ile plazma hücrelerinden oluşan kronik inflamatuar infiltrat birikmeye başlar ki; TLRs ve bu durum KiH'lerinin çeşitli hücre tiplerine diferansiasyonunu uyarır $(4,16,17)$. Fibrozis de kapak dejenerasyonlarında sık karşılaşılan bir histolojik bulgudur. Kollajen içeren ekstraselüler matriks proteinlerinin aşırı üretimi ve birikimi sonucu dokularda skarlaşma ve sertleşme olarak tanımlanır. Kalp kapaklarında kollajeni KiH'ler üretir. Kollajenin aşırı üretiminden artmış TGF-beta, tenascin ve proteoglikanlar sorumlu tutulmaktadır ki, bu sitokinlerin osteojenik, kondrojenik ve adipojenik metaplazi gibi çeşitli diferansiasyonları tetiklediği belirtilmektedir (18). Normal kalp kapakları avasküler yapıdadır. Sistemik kan akımından direkt difüzyon ile oksijenlenirler. Ancak çeşitli patolojik durumlarda neovaskülarizasyona yol açan anjiogenik faktörler eksprese etmeye başlarlar. Anti-anjiogenik faktör olan chondromodulin-l'in kalp kapaklarında angiogenezisi engelleyerek kardiak kapak fonksiyonunu koruduğu gösterilmiştir (19). Bu durum angiogenezisin kardiak kapak hastalığının progresyonuna neden olduğu görüşünü desteklemektedir ki; Akahori ve ark.'ları dejeneratif kalp kapaklarında neoanjiogenezis ve buna bağlı hemoraji odakları saptamışlardır (11). Bizim çaışmamızda da kronik inflamasyon gösteren kalp kapaklarında inflamasyon çevresinde neoanjiogenezis mevcuttu. Çalışmamızdaki mevcut klinik bulgular ve histopatolojik değişiklikler literatür ile kısmen uyumluluk göstermektedir. Ancak dejeneratif kapak hastalığı görülme yaş ortalaması literatüre göre düşük saptanmıştır. Ayrıca kadın hasta yaş ortalaması erkeklere göre biraz yüksekti. Bu dejeneratif değişikliklerin toplumuzda daha erken yaşta görülmesi ve kadınlarda daha ileri yaşta görülmesinin yaşam tarzı, cinsiyet, sosyoekonomik düzey ve çeşitli coğrafik ve etnik nedenlere bağlı olabileceğini düşünmekteyiz. Çalışmamızda hasta sayısının az olması, retrospektif histopatolojik analiz olması, hastaların klinik diagnostik verilerinin tam olarak elde edilememesi çalışmayı sınırlandıııcı faktörler olmuştur. Ancak biz yine de az veriyle de olsa çalışmamızın literatüre katkıda bulunacağını umut ediyoruz.

Sonuç olarak; kalp kapak dejenerasyonlarının kardiyovasküler risk faktörleri ile yakından ilişkili olduğu açıktır. Normale göre artmış olan hemodinamik stres ve BAK gibi yapısal anomaliler patogenezde tetikleyici rolü üstlenmektedir. Eskiden tamamen pasif dejenerasyon süreci olarak kabul edilen histopatolojik değişikliklerin aslında çok basamaklı moleküler yolaklar aracılığıyla gelişen aktif bir süreç olduğu teyit edilmiştir. Bu süreçteki başrol oyuncusunun KiH'ler olduğu ispatlanmıştır. Kapaklardaki bu yeniden yapılanma hem özgün hem de dikkate değerdir ve temel olarak hastalığın şiddeti ile doğrudan ilişkilidir. Bununla birlikte 
yeni oluşan ve yavaş bir turnover ile karakterize olduğu bilinen metaplastik doku türleri için tekrar yeniden yapılanma son derece olanaksı bir durumdur. Predispose faktörlerin yaşam boyu ortadan kaldırıması, dejeneratif metaplastik değişikliklerin oluşumunu engelleyebileceğini düşündürmektedir. Daha kapsamlı ve geniş çalışmalarla söz konusu moleküler yolakları inhibe ederek, histopatolojik metaplastik değişimleri engelleyecek çeşitli farmakolojik ajanların geliştirimesinin medikal tedaviye yardımcı olacağı ümidindeyim.

Etik Onam: Çalışma için Kahramanmaraş Sütçü İmam Üniversitesi Tıp Fakültesi Klinik Araştırmalar Etik Kurulundan onay alındı (16/05/2018 tarih, 19 nolu karar).

\section{Kaynaklar}

1. Stacey E. Mills. Histology for Pathologists. Fourth Ed. Philedelphia Pensilvanya: Lippincott Williams. 2013. 563-84

2. Kumar V, Abbas A, Aster J. Robbins \& Cotran Pathologic Basis of Disease, Nineth Edition. Philedelphia Pensilvanya: Elsevier. 2014

3. Galli D, Manuguerra R, Monaco R, Manotti L, Goldoni M, Becchi G et al. Understanding the structural features of symptomatic calcific aortic valve stenosis: A broad-spectrum clinico-pathologic study in 236 consecutive surgical cases. Int J Cardiol. 2017;228:364-74.

4. Torre M, Hwang DH, Padera RF, Mitchell RN, VanderLaan PA. Osseous and chondromatous metaplasia in calcific aortic valve stenosis. Cardiovasc Pathol. 2016;25(1):18-24.

5. Steiner I, Krbal L, Rozkoš T, Harrer J, Laco J. Calcific aortic valve stenosis: Immunohistochemical analysis of inflammatory infiltrate. Pathol Res Pract. 2012;208(4):231-4.

6. Mohler ER 3rd, Chawla MK, Chang AW, Vyavahare N, Levy RJ, Graham $L$. Identification and characterization of calcifying valve cells from human and canine aortic valves. J Heart Valve Dis. 1999;8(3):25460.

7.Steiner I, Kasparová P, Kohout A, Dominik J. Bone formation in cardiac valves: a histopathological study of 128 cases. Virchows Arch.2007;450:653-57.

8. Mirzaie M, Schultz M, Schwartz P, Coulibaly M, Schöndube F. Evidence of woven bone formation in heart valve disease. Ann Thorac Cardiovasc Surg. 2003;9(3):163-9.

9. Groom DA, Starke WR. Cartilaginous metaplasia in calcific aortic valve disease. Am J Clin Pathol. 1990;93(6):809-12.

10. Mohler ER 3rd. Mechanisms of aortic valve calcification. Am J Cardiol. 2004;94(11):1396-402.

11. Akahori H, Tsujino T, Masuyama T, Ishihara M. Mechanisms of aortic stenosis. J Cardiol. $2018 ; 71(3): 215-20$.

12. Watson KE, Boström K, Ravindranath $R$, Lam $T$, Norton $B$, Demer LL. TGF-beta 1 and 25-hydroxycholesterol stimulate osteoblast-like vascular cells to calcify. J Clin Invest. 1994;93(5):2106-13.

13. Tintut $Y$, Demer $L$. Role of osteoprotegerin and its ligands and competing receptors in atherosclerotic calcification. J Investig Med. 2006;54(7):395-401.

14. Pawade TA, Newby DE, Dweck MR. Calcification in Aortic Stenosis: The Skeleton Key. J Am Coll Cardiol. 2015;66(5):561-77.

15. Mohler ER 3rd, Gannon F, Reynolds C, Zimmerman R, Keane MG, Kaplan FS. Bone formation and inflammation in cardiac valves. Circulation. 2001;103(11):1522-8.

16. Venardos N, Nadlonek NA, Zhan Q, Weyant MJ, Reece TB, Meng $\mathrm{X}$ et al. Aortic valve calcification is mediated by a differential response of aortic valve interstitial cells to inflammation. J Surg Res. 2014;190(1):1-8.

17. West XZ, Malinin NL, Merkulova AA, Tischenko M, Kerr BA, Borden $E C$, et al. Oxidative stress induces angiogenesis by activating TLR2 with novel endogenous ligands. Nature 2010;467:972-6.

18. Jones PL, Jones FS. Tenascin-C in development and disease: gene regulation and cell function. Matrix Biol 2000;19:581-96.

19. Yoshioka M, Yuasa S, Matsumura K, Kimura K, Shiomi T, Kimura $\mathrm{N}$, et al. Chondromodulin-I maintains cardiac valvular function by preventing angio-genesis. Nat Med 2006;12:1151-9. 